\title{
Preventing fatal diseases increases healthcare costs: cause elimination life table approach
}

\author{
Luc Bonneux, Jan J Barendregt, Wilma J Nusselder, Paul J Van der Maas
}

Department of

Public Health

Erasmus University

Rotterdam, PO Box

$1738,3000 \mathrm{DR}$

Rotterdam,

Netherlands

Luc Bonneux,

medical epidemiologist

Jan J Barendregt,

mathematical

economist

Wilma J Nusselder,

demographer

Paul J Van der

Maas,

professor of public

health

Correspondence to:

Dr Bonneux

bonneux@mgz.

fgg.eur.n1

BMJ 1998;316:26-9

\begin{abstract}
Objectives: To examine whether elimination of fatal diseases will increase healthcare costs.

Design: Mortality data from vital statistics combined with healthcare spending in a cause elimination life table. Costs were allocated to specific diseases through the various healthcare registers.

Setting and subjects: The population of the Netherlands, 1988.

Main outcome measures: Healthcare costs of a synthetic life table cohort, expressed as life time expected costs.

Results: The life time expected healthcare costs for 1988 in the Netherlands were $£ 56600$ for men and $£ 80900$ for women. Elimination of fatal

diseases-such as coronary heart disease, cancer, or chronic obstructive lung disease-increases healthcare costs. Major savings will be achieved only by elimination of non-fatal disease-such as musculoskeletal diseases and mental disorders. Conclusion: The aim of prevention is to spare people from avoidable misery and death not to save money on the healthcare system. In countries with low mortality, elimination of fatal diseases by successful prevention increases healthcare spending because of the medical expenses during added life years.
\end{abstract}

\section{Introduction}

In countries with low mortality, healthcare costswhich are already substantial-are on the rise. Health promotion, on the basis of the simple idea that by preventing illness, illness related costs will be prevented, has been hailed as the solution by some. ${ }^{1}$ It is doubtful, however, whether eliminating fatal diseases would cause a decrease in chronic morbidity. Healthcare needs terminate at death. Surviving means ageing, the strongest determinant for diseases such as osteoarthritis, osteoporosis and related fractures, cognitive decline, or loss of vision or hearing.

In demography, the effects of eliminating diseases are studied by cause elimination life tables. ${ }^{2}$ In such life tables a cause of death is eradicated and the life expectancy recalculated. By linking healthcare costs specific for a disease to the life table population, the consequences of having eliminated that disease as a cause of death, as well as of a source of costs, can be estimated.

\section{Methods}

In a previous study all healthcare costs in the Netherlands in 1988 (39 800 million Dutch guilders (fl), about $£ 11400$ million at the 1988 exchange rate, for 14.8 million inhabitants) were allocated to age, sex, health- care sector, and primary diagnosis on the basis of comprehensive data on morbidity, mortality, and direct costs. ${ }^{3-5}$ About a quarter of all costs could not be allocated to a primary diagnosis, either through a lack of information or because of the non-personal nature of these costs (administration, general public health services, etc).

The healthcare costs were linked to the Dutch period life table for men and women for 1986-90. ${ }^{6}$ The expected costs represent the total costs of the life table cohort during their lifetime. These costs are divided by the initial size of the life table cohort-that is, the population at birth-to yield the life time expected costs for an individual (see appendix). The interpretation of life time expected costs is analogous to the interpretation of life expectancy. The imaginary life table cohort was subjected to the unchanging costs of 1988 and the unchanging death rates of 1986-90 until extinction. The life expectancy is the sum of all the years a life table person is expected to live; the life time expected costs are the sum of all the healthcare costs that person is expected to incur during these life years. To calculate the effect of eradication, a specific disease was eliminated both as cause of death and as cause of costs: the cause elimination life table recalculates life expectancy and life time expected costs as if the eliminated disease had never existed. The life table assumed that people lived on average for half a year in the year of death. In the year that an eliminated cause of death would have occurred, people are then at risk of death from other causes during the entire year (instead of half a year) and remain fully at risk of other causes for the added life years. Only allocated costs were considered in the cause elimination life tables. Because cause elimination life tables are interpreted as stationary populations before or after the elimination of a disease ${ }^{7}$ the costs were not discounted. Cause specific mortality data were available for 5 year age groups up to the age of $84 .^{6}$ After the age of 85 , we assumed the cause of death ratio (deaths from the specific cause divided by all deaths) and the costs remained constant with rising age. This assumption underestimates the cost of added life years in the very old. Specific causes of death are underregistered at older ages, and healthcare costs increase steadily with age..$^{3-58}$

\section{Results}

Life expectancy in the Netherlands in 1986-90 was 73.5 years for men and 80.0 years for women. The lifetime expected costs at birth for all health care totalled fl198 000 ( $\$ 56600$ ) for men and fl283000 ( $£ 80900$ ) for women. About fl155000 (£44300) for men and fl219000 (£62 600) for women was allocated to a primary diagnosis (table).

The table shows the inverse relation between fatality and costs: the highly lethal coronary heart diseases, causing nearly $19 \%$ of all deaths, account for only $2.7 \%$ of all healthcare costs. Mental disorders, including psychiatric diseases, mental handicaps, and dementia, are 
All deaths from $1986-90^{6}$ and all allocated costs (in £1000) from $1988^{5}$ caused by various disease groups and effects of elimination of these disease groups on life expectancy and life time expected costs. Numbers refer to ICD-9 codes. ${ }^{14}$ Values in parentheses are percentages. Those in life expectancy columns show relative change as consequence of elimination

\begin{tabular}{|c|c|c|c|c|}
\hline Detail & All deaths $(1986-90)$ & $\begin{array}{l}\text { All allocated costs } \\
\quad(£ 1000 ; 1988)\end{array}$ & $\begin{array}{l}\text { Life expectancy after } \\
\text { elimination (years) }\end{array}$ & $\begin{array}{l}\text { Life time expected } \\
\text { costs }(£) \text { after } \\
\text { elimination }\end{array}$ \\
\hline \multicolumn{5}{|l|}{ Men } \\
\hline Cardiovascular diseases (390-459): & $131979(39.9)$ & $480(12.8)$ & $78.8(7.1)$ & $46301(5.2)$ \\
\hline Coronary heart disease (410-414) & $69624(21.1)$ & $153(4.1)$ & $76.0(3.4)$ & $46674(6.0)$ \\
\hline Stroke (430-438) & $24524(7.4)$ & $126(3.4)$ & $74.2(0.9)$ & $43477(-1.2)$ \\
\hline Lung cancer (162) & $36859(11.1)$ & $49(1.3)$ & $74.8(1.8)$ & $45683(3.8)$ \\
\hline Colorectal cancer (153-154) & $9510(2.9)$ & $26(0.7)$ & $73.8(0.4)$ & $44201(0.4)$ \\
\hline Respiratory disease (460-519): & $29257(8.8)$ & $196(5.2)$ & $74.3(1.1)$ & $43257(-1.7)$ \\
\hline Chronic obstructive lung disease (490-496) & $20154(6.1)$ & $77(2.0)$ & $74.1(0.7)$ & $44150(0.3)$ \\
\hline Unnatural causes of death (E800-E999): & $15782(4.8)$ & $205(5.5)$ & $74.4(1.2)$ & $42617(-3.2)$ \\
\hline Musculoskeletal diseases (710-739) & $1120(0.3)$ & $300(8.0)$ & $73.6(0.04)$ & $40812(-7.3)$ \\
\hline \multicolumn{5}{|l|}{ Women } \\
\hline None & $298569(100)$ & $4930(100)$ & $80.0(100)$ & $62292(100)$ \\
\hline Cardiovascular diseases (390-459): & $126988(42.5)$ & $502(10.2)$ & $85.0(6.3)$ & $68964(10.7)$ \\
\hline Coronary heart disease $(410-414)$ & $48279(16.2)$ & $79(1.6)$ & $81.5(2.0)$ & $65994(5.9)$ \\
\hline Stroke $(430-438)$ & 35609 (11.9) & $201(4.1)$ & $81.0(1.3)$ & $62263(-0.05)$ \\
\hline Heart failure (428-429) & $12163(4.1)$ & $71(1.4)$ & $80.3(0.4)$ & $62176(-0.2)$ \\
\hline Cancer (140-208): & $76177(25.5)$ & $282(5.7)$ & $83.4(4.2)$ & $66339(6.5)$ \\
\hline Lung cancer (162) & $5650(1.9)$ & $10(0.2)$ & $80.2(0.3)$ & $62717(0.7)$ \\
\hline Colorectal cancer (153-154) & $10642(3.6)$ & $32(0.6)$ & $80.3(0.5)$ & $62810(0.8)$ \\
\hline
\end{tabular}

together responsible for only $0.6 \%$ of all deaths but account for $26 \%$ of the allocated healthcare budget. Elimination of coronary heart disease would substantially increase the burden on the healthcare budget as this would save few costs but add a considerable number of life years. Indeed, life expectancy would increase by about 1.9 years $(2.5 \%)$, while costs would jump $6 \%$. On the other hand, elimination of dementia would cause no noticeable change in life expectancy but would save $6 \%$ on the healthcare budget.

The elimination of coronary heart disease, cancer, and chronic obstructive lung disease-the present targets of health promotion-would augment healthcare costs substantially. The savings yielded by elimination of costs related to stroke and heart failure outweigh the costs associated with gains in life expectancy. Cancer is more fatal among men than among women, consequently the elimination of cancer would add more life years and therefore more costs among men.

Elimination of accidents and other unnatural causes of death adds life years and saves costs, in terms of both the high burden of morbidity and mortality. But the table shows that the largest gains are to be achieved through the elimination of mental disorders and musculoskeletal diseases: limited sources of lost life years but major sources of costs.

\section{Discussion}

Our analysis shows that lengthening life generally will increase healthcare needs, particularly needs for long term nursing care as most life years are added to old age. This is not a bad thing; prevention can hardly be blamed if it reaches its target and lowers mortality. Life saving treatment, such as antibiotic treatment of severe
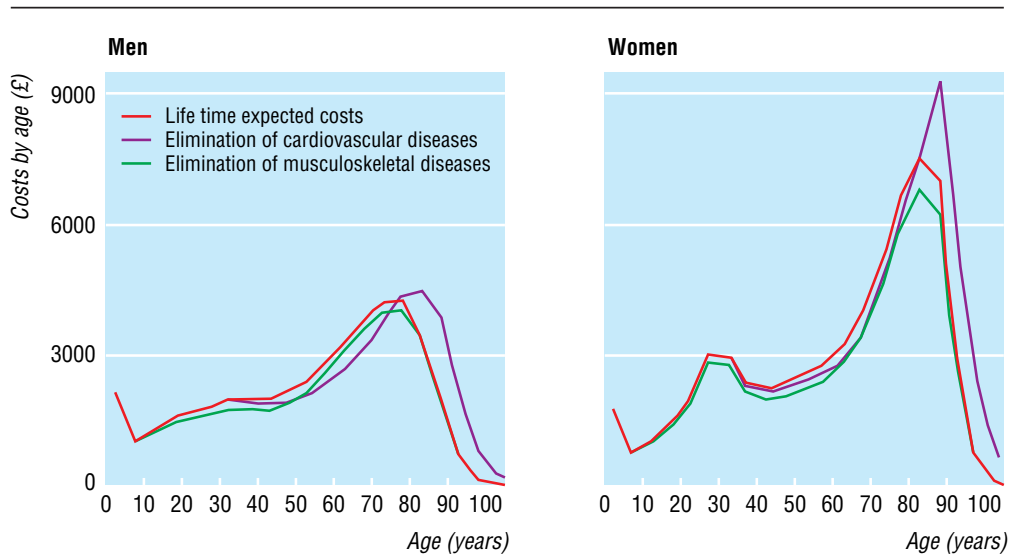

Costs by age in life table of men and women subjected to death rates and to disease allocated costs from 1988. Areas under lines are life time expected costs. Dashed lines show effects of elimination of two major disease groups: one fatal (cardiovascular disease) and one non-fatal (musculoskeletal conditions) 
infections or oral rehydration in severe diarrhoea, has the same consequences. Indeed, we firmly believe that primary prevention, such as an effective antismoking policy, is an excellent buy. But that does not imply that no bill has to be paid. Our paper contradicts popular belief that prevention might "prevent" healthcare costs. ${ }^{1}$ Acute medical costs may be averted, but the considerable needs for long term nursing care of frail elderly people can but increase.

Eliminating causes in a life table demonstrates an unquestionable truth: we all have to die. If we eliminate a specific cause of death, we simply die later from another. In the meantime we grow older, become generally more disabled, and need more care. ${ }^{9}$ In the Netherlands, cardiovascular diseases and cancer were jointly responsible for nearly $70 \%$ of all deaths, yet accounted for a mere $17 \%$ of all healthcare costs, whereas the largely non-fatal diseases of the brain, joints, and bones, causing under $2 \%$ of all deaths, generated $35 \%$ of all costs (see table). If fatal diseases are eliminated, healthcare costs during the added life years swamp the savings yielded by the eliminated disease, even if the intervention is radical and without extra costs. At any age, the imaginary population of the cause elimination life table spends less on health care per person yet total costs increase because more people remain alive, surviving to older ages when chronic morbidity and demands for health care are highest (figure).

As the debate has focused on healthcare costs, ${ }^{1}$ we took into account only medical costs. The non-medical costs of added life years, such as pensions and non-medical care for elderly people, would far outweigh any non-medical costs of disease and death. ${ }^{10}$

In view of the fact that our cost data are comprehensive, we were able to consider all healthcare spending, including long term nursing care..$^{3-5}$ Previous studies have shown that in the United States payments for acute medical care are higher in the year before death, irrespective of age at death. ${ }^{11}$ Our results do not contradict these findings but demonstrate the high burden of chronic care for non-fatal diseases, which are not determined by death.

Cause elimination life tables are simple mathematical models based on the assumption of the independence of diseases. Only primary diagnoses are taken into account, while comorbidity is ignored. In real life, many diseases are not independent, and death is often the end of a complex process. Insights are garnered from parsimonious theoretical experiments, however, precisely because they simplify a complicated reality. Taking all relevant disease interactions into account would increase needs for data and complexity of models intolerably but would not change the conclusions in a meaningful way. Indeed, only when a disease process can be postponed without postponing mortality can morbidity and healthcare needs be "compressed" by prevention. ${ }^{2}$

From a humanitarian point of view, life is preferable to death and health to illness. ${ }^{13}$ The aim of health care is not to save money but to save people from preventable suffering and death. Moreover, the medical costs of added life years are trivial. Life extension would cost about $£ 890$ to $£ 1400$ per life year added, which few would consider unacceptable. But if prevention is used as an argument for constraining future healthcare expenditures, the medical expenses
Key messages

- In countries with low mortality prevention of fatal diseases adds life years predominantly to old age, when disabling conditions are prevalent

- If fatal diseases are eliminated, the medical costs of life extension at old age will generally be higher than the costs prevented. Prevention of disabling conditions, particularly mental disorders and musculoskeletal conditions, might both lower healthcare costs and improve public health

- The aim of prevention is to save people from preventable morbidity and mortality not to save money

- For the time being, prevention of disability should have the highest priority for future research

in the added life years are not insignificant and cannot be ignored. There is no evidence that healthcare costs are increasing because citizens live unhealthier lives. In fact, quite the contrary would seem to be the case.

We have become increasingly successful at postponing mortality until advanced ages. Old age, however, is associated not only with impending death but also with dementia, social isolation, osteoarthritis, hip fractures, and loss of vision and hearing. Even humble progress in disease prevention would have a tangible impact. Any potential savings on healthcare costs would be icing on that cake.

We thank Mrs Karen Gribling-Laird for her linguistic help.

Contributors: LB had the original idea for the present study. He helped in collecting the costing data, performed the life table analysis, and wrote the paper. JJB discussed the core ideas of demographic and economic methods and helped in developing the life tables and in writing the paper. WJN did previous work in the same line of research, ${ }^{9}$ gave the demographic data, and supervised the correct use and representation of the demographic methods. She corrected previous drafts. PJVan DerM is responsible for the technology assessment methods project and its main ideas, particularly the combination of comprehensive epidemiological, economic, and demographic methods. He supervised the collection of all data and commented on previous drafts. LB, JJB, and PJVan DerM are guarantors for the scientific integrity of the paper.

Funding: This study is part of the technology assessment methods project and was funded by a grant from the Ministry of Health, Welfare, and Cultural Affairs, the Netherlands.

Conflict of interest: None.

\section{Appendix}

Life time expected costs (LEC) are calculated by

$$
L E C=\sum_{x}\left(\frac{C_{x}}{N_{x}} * L_{x}\right)
$$

where $\mathrm{C}_{\mathrm{x}}$ is the cost of all causes in the age interval $(x, x+1) \cdot N_{x}$ is the number of people in the age interval $(\mathrm{x}, \mathrm{x}+1)$ and $\mathrm{L}_{\mathrm{x}}$ the person years lived in the age inter$\operatorname{val}(\mathrm{x}, \mathrm{x}+1)$.

Eliminating a cause of death is based on the actuarial assumption that people dying from the specific cause in the age interval $x, x+1$ were considered to have been at a 0.5 year risk of dying from all other causes. The risk of dying at age $\mathrm{x}$ from all 
other causes, adjusted for competing causes, $\left(\mathrm{q}_{\mathrm{x},-\alpha}\right)$ is therefore

$$
q_{x,-a}=\frac{d_{x,-a}}{l_{x}-\frac{1}{2} d_{x, a}}
$$

where $d_{x}$ is the number of deaths in age interval ( $x$, $\mathrm{x}+1$ ) due to the cause $\alpha, d_{x,-\alpha}$ is the number of deaths in age interval $(\mathrm{x}, \mathrm{x}+1)$ due to all other causes than $\alpha$, and $l_{x}$ is the number of survivors to age $\mathrm{x}$ (of the all causes life table cohort). The life table cohort is at risk for this adjusted force of mortality from other causes until extinction. ${ }^{2}$

The expected life time costs at birth after elimination of cause $\alpha\left(\mathrm{LEC}_{-\alpha}\right)$ are given by

$$
L E C_{-a}=\sum_{x}\left(\frac{C_{x,-a}}{N_{x}} * L_{x,-a}\right)
$$

where $\mathrm{C}_{\mathrm{x},-\alpha}$ represents the costs in the age interval $(\mathrm{x}, \mathrm{x}+1)$ made for all diseases other than $\alpha$ and $\mathrm{L}_{\mathrm{x},-\alpha}$ gives the life years lived in the age interval $(x, x+1)$ after elimination of cause $\alpha$.

1 Fries JF, Koop CE, Beadle CE, Cooper PP, England MJ, Greaves RJ, et al. Reducing health care costs by reducing the need and demand for medical services. N Engl J Med 1993;329:321-5.
2 Namboodiri K, Suchindran CM. Life table techniques and their application. Orlando: Academic Press, 1987:92-109.

3 Koopmanschap MA, van Roijen L, Bonneux L. Cost of illness in the Netherlands. Rotterdam: Department of Public Health: Erasmus University, 1991.(In Dutch.)

4 van Roijen L, Koopmanschap MA, Bonneux L. The cost of illness. Ned Tijdschr Geneeskd 1992;136:74-80.(In Dutch.)

5 Koopmanschap MA, van Roijen L, Bonneux L, Bonsel GJ, Rutten FFH, van der Maas PJ. Costs of diseases in an international perspective. Eur J Public Health 1994;4:258-64.

6 Statistics Netherlands. Deaths by causes of deaths, age and gender. Voorburg: Central Bureau of Statistics, published annually.

7 Shryock HS, Siegel JS. The life table. The methods and materials of demography. San Diego/New York: Academic Press, 1976:249-71.

8 Doll R, Peto R. Sources of bias in estimating trends in cancer mortality, incidence and curability. J Natl Cancer Inst 1981;66:1270-81.

9 Nusselder WJ, Van der Velden K, Van Sonsbeek JLA, Lenior ME, Van den Bos GAM. The elimination of selected chronic diseases in a population: the compression and expansion of morbidity. Am J Public Health 1996;86:187-94.

10 Russell L. Is prevention better than cure? Washington DC: Brookings Institute, 1986:116.

11 Lubitz J, Beebe J, Baker C. Longevity and Medicare expenditures. N Engl J Med 1995;332:999-1003.

12 Fries JF. Aging, natural death, and the compression of morbidity. N EnglJ Med 1980;303:130-5.

13 Rose G. The strategy of preventive medicine. Oxford: Oxford University Press, 1992:4.

14 World Health Organisation. International statistical classification of disease, injuries and causes of death. 9th revision. Geneva: World Health Organisation, 1977.

(Accepted 26 August 1997)

\title{
First sexual intercourse: age, coercion, and later regrets reported by a birth cohort
}

\author{
Nigel Dickson, Charlotte Paul, Peter Herbison, Phil Silva
}

\begin{abstract}
Objectives: To investigate how age at first sexual intercourse is related to the reported circumstances and to determine how these corresponded to views in early adulthood about its timing.

Design: Cross sectional study within a birth cohort using a questionnaire presented by computer.

Setting: Dunedin, New Zealand in 1993-4.

Subjects: 477 men and 458 women enrolled in the Dunedin Multidisciplinary Health and Development Study, comprising $92 \%$ of survivors of the cohort. Results: The median age at first intercourse was 17 years for men and 16 years for women. Only one man $(0.2 \%)$ but $30(7 \%)$ women reported being forced to have intercourse on the first occasion. For women, there were increasing rates of coercion with younger age at first intercourse. More men than women reported that they and their partner were equally willing (77\% (316/413) v 53\% (222/419)). Mutual willingness of both partners was greater for those who reported that it was also the first time for their partner. Timing of first intercourse was considered about right by $49 \%(200 / 411)$ of men and $38 \%$ (148/388) of women. Many women (54\% (211/388) reported that they should have waited longer, and this rose to $70 \%(90 / 129)$ for women reporting intercourse before age 16 .

Conclusions: Most women regretted having sexual intercourse before age 16. First intercourse at younger
\end{abstract}

ages is associated with risks that are shared unequally between men and women. This information is important to young people themselves.

\section{Introduction}

In many developed countries, including New Zealand, there has been a substantial lowering of the age at first sexual intercourse over the past 30 years. ${ }^{1}$ Early intercourse carries increased risks of sexually transmitted diseases and unwanted pregnancies, which may result in long term health and social disadvantages. ${ }^{23}$

Individual (physical and social) and societal factors influence adolescent sexual behaviour. ${ }^{4}$ Children are exposed to sexual images through the media. Social and peer pressure may arise from the portrayal of sex as glamorous, pleasurable, and adult, while negative consequences and the responsibilities involved in sexual relationships are seldom portrayed. ${ }^{5}$ Although more liberal attitudes of society have influenced the behaviour of the current generation of young people, few studies have considered the views of young people themselves about early intercourse ${ }^{4-8}$ even though they have to bear the consequences.

The aim of our study was to investigate the circumstances of first sexual intercourse and to determine how these corresponded to views in early adulthood about its timing. Of interest was the extent of the differences in views between young men and women who reported similar sexual behaviour.
Department of Preventive and Social Medicine, University of Otago Medical School, PO Box 913, Dunedin, New Zealand Nigel Dickson senior research fellow Charlotte Paul associate professor of epidemiology Peter Herbison biostatistician

Dunedin Multidisciplinary Health and Development Unit, University of Otago Medical School Phil Silva director

Correspondence to: Dr Dickson (ndickson@gandalf. otago.ac.nz)

BMJ 1998;316:29-33 